\title{
Bilateral acute closed angle glaucoma associated with the discontinuation of escitalopram: a case report
}

\author{
Sara AIQuorain' \\ Sukayna Alfaraj ${ }^{2}$ \\ Mohammed Alshahrani ${ }^{2}$ \\ 'Department of ENT, ${ }^{2}$ Department \\ of Emergency Medicine, King Fahad \\ Hospital of the University, University \\ of Dammam, Dammam, Saudi Arabia
}

This article was published in the following Dove Press journal:

Open Access Emergency Medicine

8 September 2016

Number of times this article has been viewed

\begin{abstract}
A 45-year-old woman presented to the Emergency Department complaining of severe headache for 3 hours duration associated with bilateral blurred vision, photophobia, and one attack of vomiting. Her clinical examination revealed normal vital signs and decrease in visual acuity with hazy cornea bilaterally. There were no signs of increased intracranial pressure and no neck rigidity or meningeal signs. The patient was diagnosed with bilateral acute closed angle glaucoma (AACG) with intraocular pressure of $60 \mathrm{mmHg}$ in both eyes. She was using escitalopram for the treatment of depression, which was the only known risk factor for her condition. Standard treatment for AACG was provided. It included topical $\beta$-blocker, $\alpha$ agonists, and acetazolamide. This was followed by bilateral peripheral iridotomy. Follow-up intraocular pressure measurement revealed a value of $5 \mathrm{mmHg}$ after 24 hours, indicating complete recovery. To the best of our knowledge, this is the first case to describe AACG after stopping the medication. It is highly important that clinicians be aware of this risk factor for AACG and have high index of suspicion in such patients with vision-threatening condition even after discontinuing the medication, because the risk persists for some time.
\end{abstract}

Keywords: acute closed angle glaucoma, escitalopram, intraocular pressure

\section{Background}

By 2020, 79.6 million people will have open and closure angle glaucoma, and this will be the second leading cause of blindness in the world. ${ }^{1}$ Angle-closure glaucoma is characterized by narrowing or closure of the anterior chamber angle of the eye. Patients present with decreased vision, halos around lights, headache, severe eye pain, and vomiting. Eye examination usually shows conjunctival redness, corneal edema or clouding, shallow anterior chambers, and mid-dilated pupils (4-6 mm) that react poorly to light. Angle-closure glaucoma is divided into two main groups: primary - in which patients are anatomically predisposed to this type of glaucoma with no identifiable risk factor - and secondary - which includes the presence of known cause for narrowing or closure of the anterior chamber angle. ${ }^{2}$ Drugs were found to be among those secondary causes. The eye is prone to drug-related adverse effects due, in part, to its extensive blood supply and relatively small mass. Examples of these drugs include topical anticholinergic or sympathomimetic dilating drops, some antidepressants such as tricyclic and selective serotonin reuptake inhibitor (SSRI), monoamine oxidase inhibitors, antihistamines, antiparkinsonian drugs, antipsychotic medications, and antispasmolytic agents. ${ }^{3-5}$ According to one study, $33 \%$ of acute closed angle glaucoma is secondary to over-the-counter and prescription medications. ${ }^{6}$
Correspondence: Mohammed Alshahrani Department of Emergency Medicine, College of Medicine, King Fahad Hospital of the University, University of Dammam, PO Box 40236, AlKhobar, Saudi Arabia Tel +966556966663

Email msshahrani@ud.edu.sa 
We reported a rare case of a 45 -year-old woman with typical symptoms and signs of bilateral acute closed angle glaucoma with the risk factor of previous use of SSRI medicine for her depression symptoms (escitalopram), which she stopped recently.

\section{Case presentation History}

Here, we describe the case of a 45-year-old woman known to have controlled hypertension for 5 years for which she was taking oral beta-blocker medications, and she also had a history of depression for 1 year. The patient presented to the Emergency Department complaining of moderate right-sided headache associated with bilateral blurred vision, photophobia, and one attack of vomiting. Two hours later, the headache shifted to the left side and became much more severe. There was no history of previous similar episodes of headache, head trauma, fever, neck rigidity, rash, loss of consciousness, aphasia, weakness, numbness, and diplopia. In addition, there was also no previous history of eye trauma or surgery or family history of glaucoma.

The patient gave the history of using escitalopram for the treatment of depression for 1 year, which she stopped suddenly 1 month prior to presentation. The patient's vital signs were all normal. On physical examination, cranial nerves were intact. Neurological examination showed normal sensory and motor systems, and reflexes and normal cerebellar function. Neck movement was normal, and no meningeal signs were present. Eye examination revealed normal white sclera and middilated pupils, which were nonreactive to light. Visual acuity examination showed results of 0.3 and 0.4 for right and left eyes, respectively. The cornea was slightly hazy in both eyes. Intraocular pressure (IOP) was $60 \mathrm{mmHg}$ in both eyes. Retinal examination showed a cup-to-disc ratio of 0.4 and 0.2 for right and left eyes, respectively, with no other retinal findings on fundoscopy. Pentacam examination of the eyes is shown in Figures 1 and 2. Results of all laboratory investigations, including complete blood count, renal, liver function, and electrolytes, were within the normal range. Nonenhanced transaxial computed tomography scan of the brain was done and showed preserved gray-white matter with no obvious hemorrhage. There were no space-occupying lesions, mass effect, or midline shift, and also no hydrocephalus, and orbit and sinuses were normal.

\section{Treatment}

The patient was treated for acute closed angle glaucoma secondary to escitalopram with IV acetazolamide (Diamox), mannitol, timolol, Alphagan, pilocarpine eye drops, followed next day by bilateral peripheral iridotomy. Follow-up of the patient after 48 hours showed normal anterior chambers, with an IOP of $5 \mathrm{mmHg}$ for each eye, which indicates a complete recovery. As per the University of Dammam Institutional Review Board, case reports do not need ethical approval or patient consent, as long as there is no intervention encountered and no identifiers for the patients appear in the report. Therefore, neither ethical approval nor patient consent was required for this case report.

\section{Discussion}

Our case describes a patient who presented to the emergency department with typical symptoms and signs of acute closed angle glaucoma, and the identified risk factors were hypertension and escitalopram use for her depression for 1 year (which she stopped recently). In this case, we are in favor of blaming this antidepressant drug over the systemic hypertension as the risk factor for her presenting condition because her blood pressure was controlled by using a beta blocker, which was found by Langman et $\mathrm{al}^{7}$ in a cohort of 27,080 hypertensive patients to be decreasing the risk of glaucoma in hypertensive patients.

Escitalopram belongs to a group of antidepressant medicines known as SSRIs. Serotonin (5-HT) receptors have been shown to be present in human eyes and present at a higher concentration in mammalian ciliary body and cornea than in nonmammalian species. ${ }^{89}$ Meyer et $\mathrm{al}^{10}$ showed that topical application of SSRI increases IOP in rabbits' eyes where serotonin raised the IOP in a dose-dependent manner over time, with a maximum reached within 1 hour. Similarly, in a study of 20 consecutive depressed patients, administration of a single dose of $20 \mathrm{mg}$ fluoxetine increased the IOP by $4 \mathrm{mmHg} .{ }^{11}$

There are few case reports in the literature that described acute glaucoma after the use of escitalopram. But to the best of our knowledge, this is the first case to describe the condition after stopping the medication. However, it has been reported by Fava et $\mathrm{a}^{12}$ in a large systematic review, including 15 randomized controlled studies, four open trials, four retrospective studies, and 38 case reports, in which the withdrawal effects of SSRIs were found to be multisystem. Eye manifestations were reported as visual changes and blurred vision. This visual effect of SSRIs can be explained by delayed action of this class of drugs. The mechanism by which SSRIs result in angle-closure glaucoma remains uncertain. It has been postulated that serotonin is responsible for increased pupil dilation and aqueous production..$^{13}$ Another study suggested that the anticholinergic effects of the medications cause pupil dilation. ${ }^{14}$ Zelefsky et a $\mathrm{l}^{15}$ reported a similar case of bilateral angle-closure glaucoma that was resistant to medical and surgical treatment after 4 weeks of use of escitalopram, and complete recovery was achieved only after the discontinuation of the medication. The similarity between our case and the case described by Zelefsky et $\mathrm{al}^{15}$ is that both were resistant 

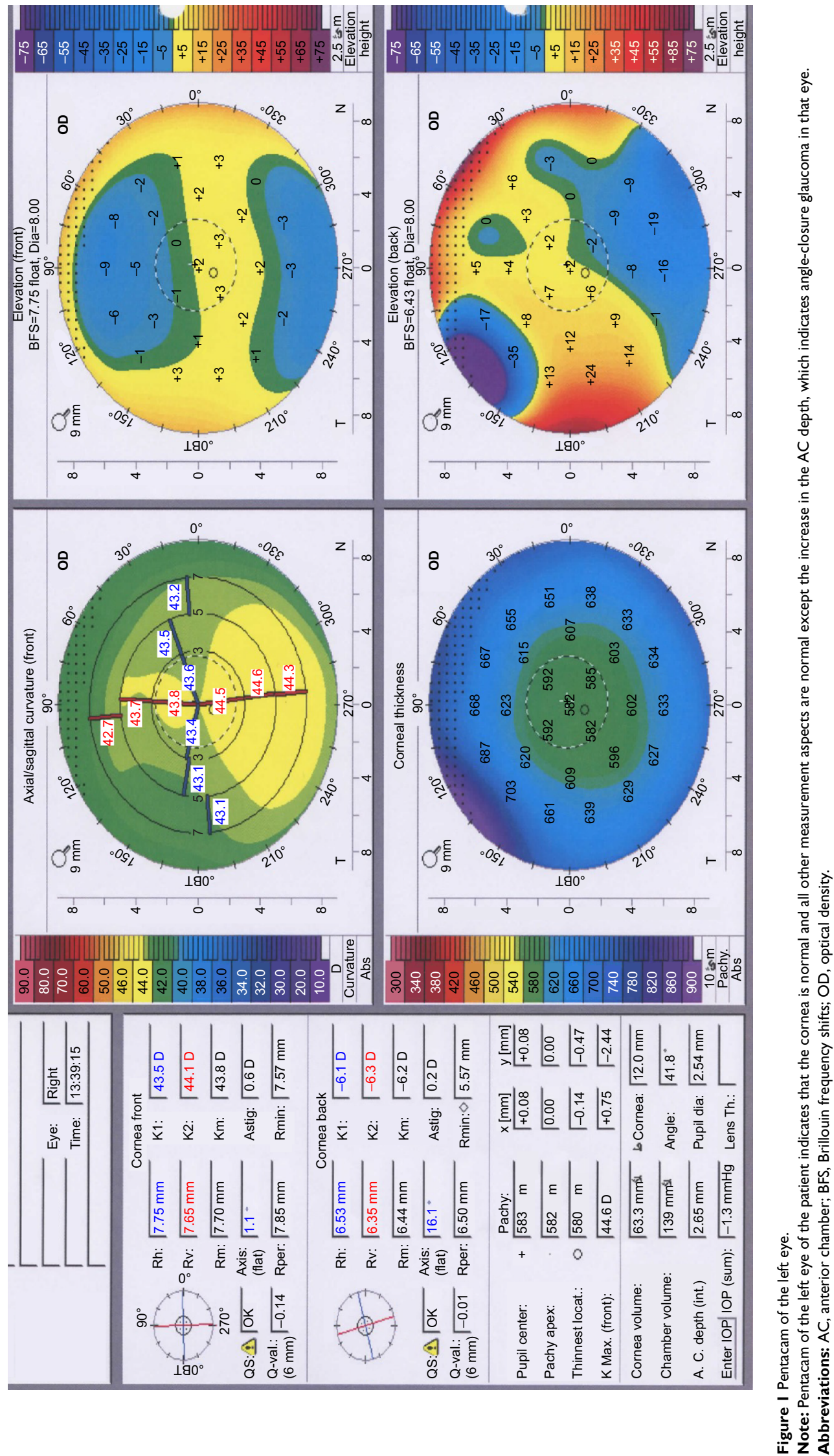

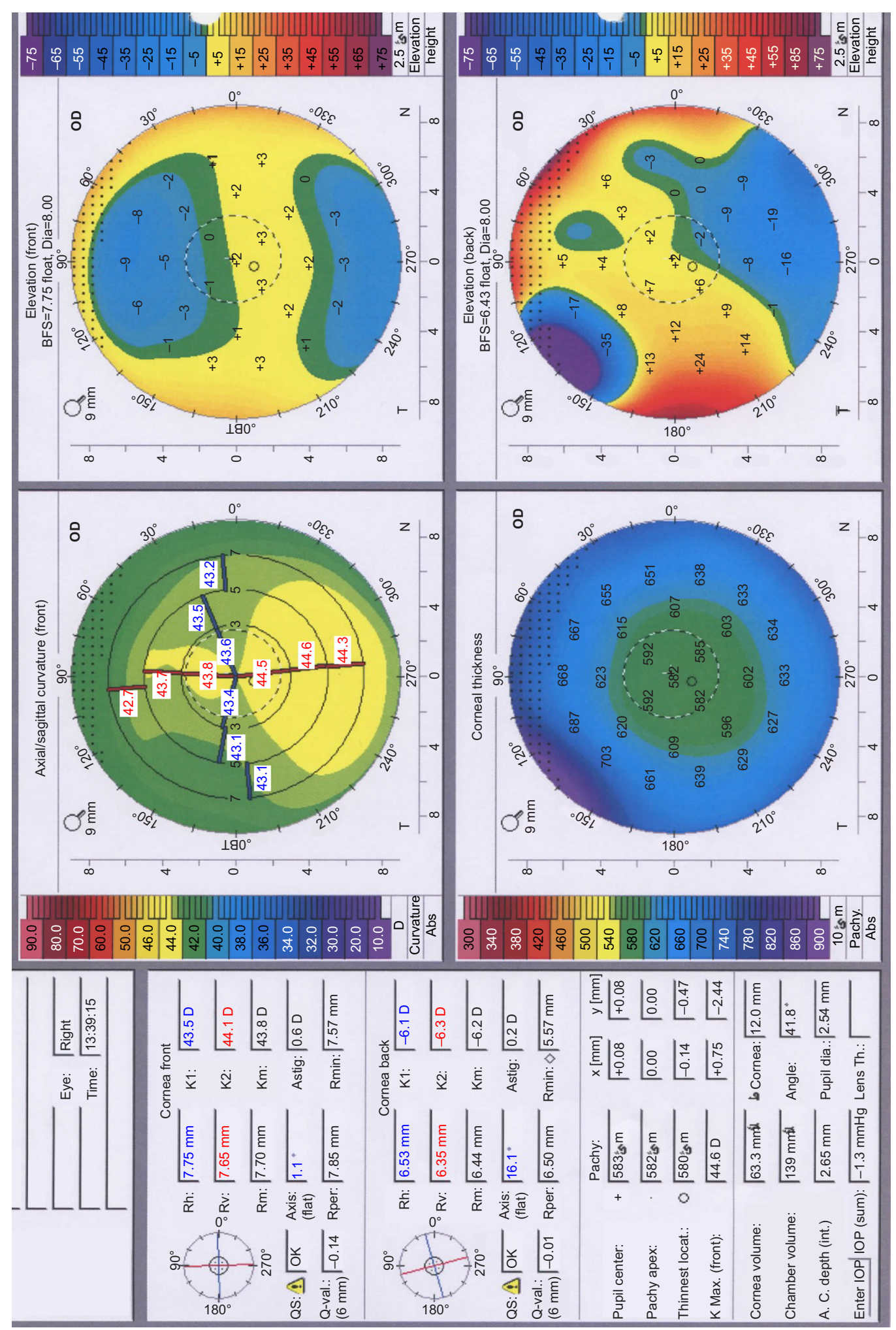

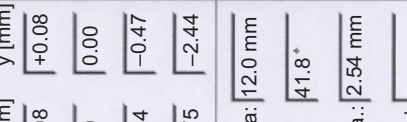

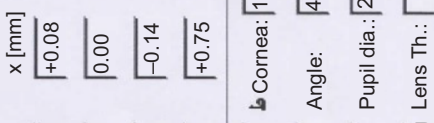

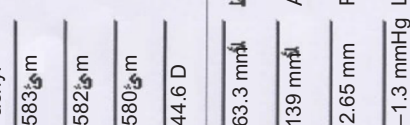


to medical treatments initially, but our case responded to laser peripheral iridotomy whereas Zelefsky et al's ${ }^{15}$ case only responded after stopping the offending drug, which was stopped already in our case by the patient.

This report serves to highlight the importance of constant vigilance when diagnosing and treating acute glaucoma, particularly in cases with no clear risk factors and resistant to usual treatment, this case did not respond to the normal range of treatments for the condition.

\section{Conclusion}

The correlation between the usage of SSRIs and the development of acute glaucoma has been described and discussed previously in the literature. Whether there is a correlation between the development of acute glaucoma and SSRIs after discontinuing the medication needs to be elucidated by further studies.

\section{Disclosure}

The authors report no conflicts of interest in this work.

\section{References}

1. Quigley HA, Broman AT. The number of people with glaucoma worldwide in 2010 and 2020. Br J Ophthalmol. 2006;90(3):262-267.

2. See JL, Chew PT. Angle-closure Glaucoma. In: Yanoff M, Duker JS, editors. Ophthalmology. 3rd ed. St Louis, MO: Mosby; 2009:1162.
3. Razeghinejad MR, Myers JS, Katz LJ. Iatrogenic glaucoma secondary to medications. Am J Med. 2011;124:20-25.

4. Tripathi RC, Tripathi BJ, Haggerty C. Drug induced glaucoma's: mechanisms and management. Drugs Saf. 2003;26(11):749-767.

5. Lachkar Y, Bouassida W. Drug-induced acute angle closure glaucoma. Curr Opin Ophthalmol. 2007;18(2):129-133.

6. Rudkin AK, Gray TL, Awadalla M, Craig JE. Bilateral simultaneous acute angle closure glaucoma precipitated by non-prescription cold and flu medication. Emerg Med Australas. 2010;22(5):477-479.

7. Langman MJ, Lancashire RJ, Cheng KK, Stewart PM. Systemic hypertension and glaucoma: mechanisms in common and co-occurrence. Br J Ophthalmol. 2005;89:960-963.

8. Barrett JE, Vanover KE. 5-HT receptors as targets for the development of novel anxiolytic drugs: models, mechanisms and future directions. Psychopharmacology (Berl). 1993;112(1):1-12.

9. Osbourne NN, Tobin AB. Serotonin accumulating cells in the iris-ciliary body and cornea of various species. Exp Eye Res. 1987;44:731-746.

10. Meyer-Bothling U, Bron AJ, Osborne NN. Topical application of serotonin or the 5-HTX-agonist 5-CT intraocular pressure in rabbits. Invest Ophthalmol Vis Sci. 1993;34:3035-3042.

11. Osbourne NN. Serotonin and melatonin in the iris/ciliary processes and their involvement in intraocular presence. Acta Neurobiol Exp. 1994;54(Suppl):57-64.

12. Fava GA, Gatti A, Belaise C, Guidi J, Offidani E. Withdrawal symptoms after selective serotonin reuptake inhibitor discontinuation: a systematic review. Psychother Psychosom. 2015;84:72-81.

13. Santaella RM, Fraunfelder FW. Ocular adverse effects associated with systemic medications. Drugs. 2007;67(1):75-93.

14. Costagliola C, Parmeggiani F, Sebastiani A. SSRIs and intraocular pressure modifications: evidence, therapeutic implications and possible mechanisms. CNS Drugs. 2004;18(8):475-484.

15. Zelefsky JR, Fine HF, Rubinstein VJ, Hsu IS, Finger PT. Escitalopraminduced uveal effusions and bilateral angle closure glaucoma. $\mathrm{Am} \mathrm{J}$ Ophthalmol. 2006;141(6):1144-1147.
Open Access Emergency Medicine

\section{Publish your work in this journal}

The Open Access Emergency Medicine is an international, peerreviewed, open access journal publishing original research, reports, editorials, reviews and commentaries on all aspects of emergency medicine. The manuscript management system is completely online and includes a very quick and fair peer-review system, which is all

\section{Dovepress}

easy to use. Visit http://www.dovepress.com/testimonials.php to read real quotes from published authors. 